\title{
Decreased expression of peroxisome proliferator- activated receptor alpha indicates unfavorable outcomes in hepatocellular carcinoma
}

This article was published in the following Dove Press journal: Cancer Management and Research

\author{
Yong-bo Xiao, ${ }^{1,2, *}$ \\ Shao-hang Cai ${ }^{1,2, *}$ \\ Li-li Liu',2 \\ Xia Yang ${ }^{1,2}$ \\ Jing-ping Yun ${ }^{1,2}$
}

'State Key Laboratory of Oncology in South China, Collaborative Innovation Center for Cancer Medicine,

Sun Yat-sen University Cancer Center, Guangzhou 510060, China;

${ }^{2}$ Department of Pathology, Sun Yat-sen University Cancer Center, Guangzhou 510060 , China

*These authors contributed equally to this work
Correspondence: Jing-ping Yun Department of Pathology, Sun Yat-sen University Cancer Center, No. 65I

Dongfeng East Road, Guangzhou 510060,

China

Tel/fax +862087342272

Email yunjp@sysucc.org.cn
Introduction: Hepatocellular carcinoma (HCC) has a close relationship with lipid metabolism. Peroxisome proliferator-activated receptor $\alpha$ (PPAR $\alpha$ ) plays a crucial role in the regulation of fatty acid oxidation in the liver. However, the role of PPAR $\alpha$ in HCC remains unclear.

Methods: A total of $804 \mathrm{HCC}$ specimens were collected to construct a tissue microarray and for immunohistochemical analysis. The relationship between PPAR $\alpha$ expression and clinical features of HCC patients was analyzed. Kaplan-Meier analysis was conducted to assess the prognostic value of PPAR $\alpha$ expression levels.

Results: The expression of PPAR $\alpha$ in HCC was noticeably decreased in HCC tissues. HCC patients with high levels of PPAR $\alpha$ expression in cytoplasm had smaller tumors $(P=0.027)$, less vascular invasion $(P=0.049)$, and a higher proportion of complete involucrum $(P=0.038)$. Kaplan-Meier analysis showed that HCC patients with low PPAR $\alpha$ expression in the cytoplasm had significantly worse outcomes in terms of overall survival $(P<0.001)$, disease-free survival $(P=0.024)$, and the probability of recurrence $(P=0.037)$. Similarly, overall survival was significantly shorter in HCC patients with negative PPAR $\alpha$ expression in the nucleus $(P=0.034)$. Multivariate Cox analyses indicated that tumor size ( $P=0.001)$, TNM stage $(P<0.001)$, vascular invasion $(P<0.001)$, and PPAR $\alpha$ expression in the cytoplasm $(P<0.001)$ were found to be independent prognostic variables for overall survival.

Conclusion: Our data revealed that PPAR $\alpha$ expression was decreased in HCC samples. High PPAR $\alpha$ expression was correlated with longer survival times in HCC patients, and served as an independent factor for better outcomes. Our study therefore provides a promising biomarker for prognostic prediction and a potential therapeutic target for HCC.

Keywords: peroxisome proliferator-activated receptors $\alpha$, lipid metabolism, hepatocellular carcinoma, prognostic biomarker

\section{Introduction}

Hepatocellular carcinoma (HCC) is the third most frequent cause of cancer death worldwide. ${ }^{1}$ Due to the extensive heterogeneity in clinical presentation and tumor biology, the classification for HCC therapy is complicated. ${ }^{2,3}$ One of the heterogeneities of HCC is tumor metabolic reprogramming. Although most tumors share common metabolic transformations like aerobic glycolysis, ${ }^{4}$ the metabolic phenotypes of cancer cells are highly diverse because of the tumor microenvironment. For example, primary ovarian cancer cells have highly activated lipogenesis in order to supply the lipid required for uncontrolled cell proliferation. However, when ovarian cancer metastasizes to omental fat that contains a microenvironment abundant in adipocytes, the cancer cells are metabolically reprogrammed to favor more lipid oxidation using adipocyte-derived fatty 
acids. ${ }^{5}$ In HCC, due to the high rate of nutrient consumption and lack of vasculature, HCC cells frequently experience a stressful metabolic microenvironment, which is characterized by oxygen and nutrient deficiency. ${ }^{6}$ There may therefore be adaptive metabolic reprogramming that develops within HCC cells that allows them to cope with the stressful metabolic microenvironment. A study conducted by Wang et al revealed that $\mathrm{HCC}$ cells display distinct lipid levels, which are positively correlated with HCC cell survival in stressful metabolic microenvironments. ${ }^{7}$ In addition, acetyl-coenzyme A carboxylase alpha plays an important role in HCC cells by promoting fatty acid synthesis and thereby increasing the lipid content of these cells.

Another important approach to increasing the lipid content in HCC cells, in addition to increasing fatty acid synthesis, is to inhibit fatty acid oxidation. Previous studies have confirmed that peroxisome proliferator-activated receptors (PPARs) play a crucial role in regulating fatty acid oxidation and the upstream rate-limiting enzyme of fatty acid oxidation, carnitine palmitoyltransferase $1 .^{8}$ Despite similar structures, the three PPAR isotypes $\alpha, \beta$, and $\gamma$ vary greatly in their tissue distribution, pharmacology, type of endogenous ligand, and biological effects. Especially in the liver, PPAR $\alpha$ acts as a master regulator of liver metabolism. PPAR $\alpha$-regulated processes are thought to be involved in all liver diseases. ${ }^{9}$ Owing to the importance of PPAR $\alpha$ in metabolism, many studies have examined the role of PPAR $\alpha$ in tumorigenesis, with some studies implicating it in the promotion and development of cancer, with others presenting evidence for an anti-tumorigenic role. ${ }^{10}$ PPAR $\alpha$ activation increases proliferation in breast cancer cell lines and in a renal cell carcinoma cell line, ${ }^{11,12}$ and its persistent activation causes liver cancer in rodents, whereas PPAR $\alpha$ null mice have been shown to be resistant to the hepatocarcinogenic effects of PPAR $\alpha$ agonists. ${ }^{13}$ Despite these findings, the role of PPAR $\alpha$ as either a tumor suppressor or inducer in HCC remains unclear, and may differ in different species.

In this study, we investigated the role of PPAR $\alpha$ in human HCC. We showed that PPAR $\alpha$ expression was positively correlated with overall survival in patients with HCC, and therefore it provides a promising biomarker for prognostic prediction and is a potential therapeutic target for the clinical management of HCC.

\section{Subjects and methods Subjects}

A total of 804 paraffin-embedded HCC specimens collected between January 2000 and December 2010 were obtained from the archives of the Department of Pathology of Sun Yatsen University Cancer Center. None of the patients received any chemotherapy or radiotherapy prior to surgery. The follow-up period was defined as the interval from the date of surgery to the date of death or the last follow-up. This study was approved by the Institute Research Medical Ethics Committee of Sun Yat-sen University Cancer Center. All tissues were anonymous and the requirement of obtaining informed consent was waived by the Institute Research Medical Ethics Committee of Sun Yat-sen University Cancer Center.

\section{Tissue microarray (TMA) construction and immunohistochemistry (IHC)}

The TMA slides included 804 HCC tissues along with their adjacent normal tissues. Using a tissue array instrument (Minicore; Excilone, Elancourt, France), each tissue core was punched (diameter: $0.6 \mathrm{~mm}$ ) from the marked areas and re-embedded. All specimens were fixed in $4 \%$ paraformaldehyde in $0.1 \mathrm{M}$ phosphate buffer for 24 hours and embedded in paraffin wax. Following this, the paraffin-embedded HCC sections were sliced into 4- $\mu \mathrm{m}$ slices and mounted onto glass slides. After dewaxing, the slides were treated with $3 \%$ hydrogen peroxide in methanol and blocked using a biotin blocking kit (Dako Denmark A/S, Glostrup, Denmark). After blocking, the slides were incubated with a PPAR $\alpha$ antibody (ab8934, 1:1000; Abcam, Cambridge, UK) overnight in a moist chamber at $4^{\circ} \mathrm{C}$. After washing three times in PBS, the slides were incubated with biotinylated goat anti-mouse antibodies for 1 hour. The slides were then stained with 3,3'-diaminobenzidine tetrahydrochloride. Finally, the slides were counterstained with Mayer's hematoxylin and observed under a microscope.

The level of PPAR $\alpha$ protein expression was determined by semiquantitative IHC detection. Intensity was scored according to the standard: "0" (negative staining); "1" (weak staining); "2" (moderate staining); and "3" (strong staining). The final score was calculated by multiplying the percentage of positive expression by the intensity score. The scores were independently determined by two pathologists. The median IHC score was chosen as the cut off value for defining high and low expression.

\section{Statistical analysis}

Statistical analysis was performed using SPSS (version 16.0; SPSS Inc, Chicago, IL, USA). Student's $t$-test and Pearson's $\chi^{2}$ test, or Fisher's exact test, were chosen for examining the correlations between PPAR $\alpha$ expression level and the clinical and pathological variables. Survival curves were constructed using the Kaplan-Meier method (log-rank test). 
A multivariate Cox proportional hazards regression model was used to evaluate the independence of PPAR $\alpha$ in predicting outcomes. Differences were defined as significant for $P$-values $<0.05$.

\section{Results \\ Expression of PPAR $\alpha$ in HCCTMA tissues}

First, paraffin-embedded HCC tissues were collected to detect PPAR $\alpha$ expression $(n=804)$. PPAR $\alpha$ was mainly expressed in the cytoplasm of HCC liver cancer cells, with only a small fraction of cells showing expression in the nucleus. The PPAR $\alpha$ IHC score for HCC tissue was $0.74 \pm 0.61$, being significantly lower than normal liver tissue which had a score of $1.22 \pm 0.65(P<0.001$, Figure 1).

\section{Association of cytoplasmic PPAR $\alpha$ with HCC clinical features}

To determine the potential clinical significance of PPAR $\alpha$ in HCC, the relationship between PPAR $\alpha$ and the clinical features of HCC patients was evaluated. Using the median IHC score in the tumor tissue (IHC score 0.9), a high level of PPAR $\alpha$ expression was found in $15.3 \%(123 / 804)$ of cases. HCC patients with high levels of PPAR $\alpha$ expression had smaller tumor sizes $(P=0.027)$, less vascular invasion $(P=0.049)$, and a higher proportion of complete involucrum $(P=0.038)$, as shown in Table 1 . Since HCC is a maledominant liver disease, we also compared the expression of PPAR $\alpha$ in male and female. However, we did not observe a significant difference of PPAR $\alpha$ expression between male and female $(0.75 \pm 0.62$ vs $0.69 \pm 0.56, P=0.42)$.

\section{Association of PPAR $\alpha$ expression in the nucleus and clinical features in HCC}

There were only 24 tissues among the 804 samples that showed positive PPAR $\alpha$ expression in the nucleus. Accordingly, we also compared tissues with negative and positive PPAR $\alpha$ expression in the nucleus. As shown in Table 2, data showed that HCC patients with negative PPAR $\alpha$ expression in the nucleus often had larger tumors $(P=0.014)$. Among the HCC patients with positive PPAR $\alpha$ expression in the nucleus, a significantly lower proportion had poor undifferentiated tumors $(P<0.001)$, were TNM stage III-IV $(P=0.036)$ and had an incomplete involucrum $(P=0.004)$. We also compared the
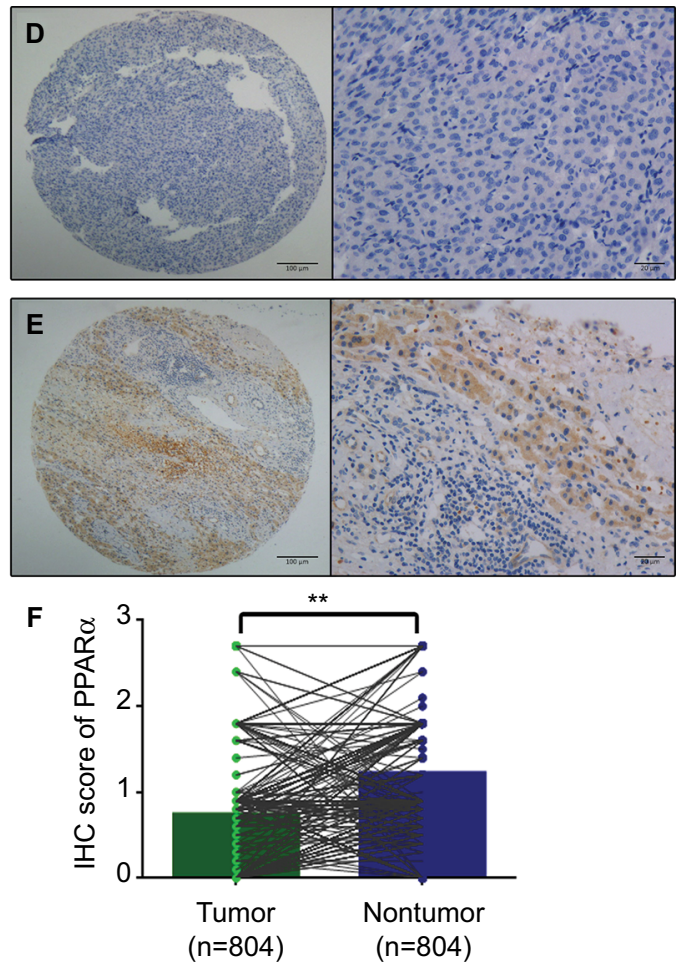

Figure I PPAR $\alpha$ is mainly expressed in the cytoplasm with only a few tissues showing nuclear expression.

Notes: Representative images of PPAR $\alpha$ (cytoplasm) expression in HCC tissues with strong (A), moderate (B), weak (C), and negative (D) expression are shown. Representative images of PPAR $\alpha$ expression in a nontumor sample are also shown (E) (left panel: magnification $\times 100$; right panel: magnification $\times 400$ ). PPAR $\alpha$ expression is decreased in HCC tissues compared with the corresponding nontumor tissue as assessed by IHC (**P<0.00I) (F).

Abbreviations: PPAR $\alpha$, peroxisome proliferator-activated receptor $\alpha$; HCC, hepatocellular carcinoma; IHC, immunohistochemistry. 
Table I Association between PPAR $\alpha$ expression in the cytoplasm and the clinical features of hepatocellular carcinoma

\begin{tabular}{|c|c|c|c|}
\hline \multirow[t]{2}{*}{ Variable } & \multicolumn{2}{|c|}{ PPARa in cytoplasm } & \multirow[t]{2}{*}{$P$-value } \\
\hline & $\begin{array}{l}\text { High } \\
\text { expression }\end{array}$ & $\begin{array}{l}\text { Low } \\
\text { expression }\end{array}$ & \\
\hline Sample size & 123 & 681 & \\
\hline Age, years & $50.60 \pm 11.76$ & $48.56 \pm 11.94$ & $0.08 I$ \\
\hline Gender & & & 0.498 \\
\hline Male & III (I3.8\%) & $600(74.6 \%)$ & \\
\hline Female & $12(1.5 \%)$ & $81(10.1 \%)$ & \\
\hline $\mathrm{HBsAg}$ & & & 0.693 \\
\hline Positive & 104 (I2.9\%) & $566(70.4 \%)$ & \\
\hline Negative & $19(2.4 \%)$ & $115(14.3 \%)$ & \\
\hline AFP, $n g / m L$ & & & 0.394 \\
\hline$<20$ & $31(3.9 \%)$ & $148(18.4 \%)$ & \\
\hline$\geq 20$ & 92 (II.4\%) & $533(66.3 \%)$ & \\
\hline Cirrhosis & & & 0.619 \\
\hline Yes & $102(12.7 \%)$ & $55 I(68.6 \%)$ & \\
\hline No & $21(2.6 \%)$ & $129(16.1 \%)$ & \\
\hline Tumor size, $\mathrm{cm}$ & & & 0.027 \\
\hline$<5$ & $40(4.9 \%)$ & $158(19.7 \%)$ & \\
\hline$\geq 5$ & $83(10.3 \%)$ & $523(65.1 \%)$ & \\
\hline Tumor multiplicity & & & 0.927 \\
\hline Single & 81 (10.1\%) & $45 \mathrm{I}(56.1 \%)$ & \\
\hline Multiple & $42(5.2 \%)$ & $230(28.6 \%)$ & \\
\hline Differentiation & & & 0.390 \\
\hline Well-moderate & $13(1.6 \%)$ & $56(6.9 \%)$ & \\
\hline Poor-undifferentiated & $110(13.7 \%)$ & $625(77.8 \%)$ & \\
\hline TNM stage & & & 0.790 \\
\hline I-II & $50(6.2 \%)$ & $286(35.6 \%)$ & \\
\hline III-IV & $73(9.1 \%)$ & $395(49.1 \%)$ & \\
\hline Vascular invasion & & & 0.049 \\
\hline Yes & $108(13.5 \%)$ & $546(67.9 \%)$ & \\
\hline No & $15(1.9 \%)$ & $134(16.7 \%)$ & \\
\hline Involucrum & & & 0.038 \\
\hline Complete & $62(7.7 \%)$ & $274(34.2 \%)$ & \\
\hline Incomplete & 61 (7.6\%) & 405 (50.5\%) & \\
\hline Lymph node metastasis & & & 0.097 \\
\hline Positive & $3(0.4 \%)$ & $42(5.2 \%)$ & \\
\hline Negative & $120(14.9 \%)$ & 638 (79.5\%) & \\
\hline Distant metastasis & & & 0.050 \\
\hline Positive & $6(0.8 \%)$ & 72 (9.0\%) & \\
\hline Negative & $116(14.5 \%)$ & $604(75.7 \%)$ & \\
\hline
\end{tabular}

Abbreviations: $\operatorname{PPAR} \alpha$, peroxisome proliferator-activated receptor $\alpha$; $\mathrm{HBsAg}$, hepatitis B virus surface antigen; AFP, $\alpha$-fetoprotein.

PPAR $\alpha$ between virus-induced HCC and non-virus-induced HCC. We found no difference of PPAR $\alpha$ expression between them either in the cytoplasm $(0.71 \pm 0.55$ vs $0.75 \pm 0.63$, $P=0.47)$ or in the nuclei $(0.01 \pm 0.08$ vs $0.01 \pm 0.07, P=0.53)$.

\section{Association of PPAR $\alpha$ expression with clinical outcomes in HCC patients}

To determine the prognostic impact of PPAR $\alpha$ expression on HCC patients, we conducted a Kaplan-Meier survival analysis using data from the $804 \mathrm{HCC}$ patients enrolled in
Table 2 Association between PPAR $\alpha$ expression in the nucleus and the clinical features of hepatocellular carcinoma

\begin{tabular}{|c|c|c|c|}
\hline \multirow[t]{2}{*}{ Variable } & \multicolumn{2}{|c|}{ PPAR $\alpha$ in nucleus } & \multirow[t]{2}{*}{$P$-value } \\
\hline & $\begin{array}{l}\text { Positive } \\
\text { expression }\end{array}$ & $\begin{array}{l}\text { Negative } \\
\text { expression }\end{array}$ & \\
\hline Sample size & 24 & 780 & \\
\hline Age, years & $51.17 \pm 11.54$ & $48.80 \pm 11.93$ & 0.340 \\
\hline Gender & & & 0.250 \\
\hline Male & $23(2.9 \%)$ & $688(85.6 \%)$ & \\
\hline Female & I (I.I\%) & $92(11.4 \%)$ & \\
\hline $\mathrm{HBsAg}$ & & & 0.578 \\
\hline Positive & $19(2.4 \%)$ & 651 (80.9\%) & \\
\hline Negative & $5(0.6 \%)$ & $129(16.1 \%)$ & \\
\hline AFP, $n g / m L$ & & & 0.744 \\
\hline$<20$ & $6(0.8 \%)$ & $607(75.5 \%)$ & \\
\hline$\geq 20$ & I8 (2.2\%) & $173(2 \mid .5 \%)$ & \\
\hline Cirrhosis & & & 0.420 \\
\hline Yes & $18(2.2 \%)$ & $635(79.0 \%)$ & \\
\hline No & $6(0.8 \%)$ & $144(18.0 \%)$ & \\
\hline Tumor size, $\mathrm{cm}$ & & & 0.014 \\
\hline$<5$ & II (I.4\%) & $187(23.2 \%)$ & \\
\hline$\geq 5$ & $13(1.6 \%)$ & $593(73.8 \%)$ & \\
\hline Tumor multiplicity & & & 0.071 \\
\hline Single & $20(2.5 \%)$ & $512(63.7 \%)$ & \\
\hline Multiple & $4(0.5 \%)$ & $268(33.3 \%)$ & \\
\hline Differentiation & & & $<0.001$ \\
\hline Well-moderate & $7(0.9 \%)$ & $62(7.7 \%)$ & \\
\hline Poor-undifferentiated & $17(2.1 \%)$ & $718(89.3 \%)$ & \\
\hline TNM stage & & & 0.036 \\
\hline I-II & 15 (I.9\%) & $320(39.8 \%)$ & \\
\hline III-IV & $9(1.1 \%)$ & $460(57.2 \%)$ & \\
\hline Vascular invasion & & & 0.066 \\
\hline Yes & I (0.1\%) & 148 (I8.4\%) & \\
\hline No & $23(2.9 \%)$ & $631(78.6 \%)$ & \\
\hline Involucrum & & & 0.004 \\
\hline Complete & $17(2.1 \%)$ & $319(39.8 \%)$ & \\
\hline Incomplete & $7(0.9 \%)$ & $459(57.2 \%)$ & \\
\hline Lymph node metastasis & & & 0.226 \\
\hline Positive & $0(0 \%)$ & 45 (5.6\%) & \\
\hline Negative & $24(3.0 \%)$ & 734 (91.4\%) & \\
\hline Distant metastasis & & & 0.102 \\
\hline Positive & $0(0 \%)$ & $78(9.8 \%)$ & \\
\hline Negative & $24(3.0 \%)$ & $696(87.2 \%)$ & \\
\hline
\end{tabular}

Abbreviations: PPAR $\alpha$, peroxisome proliferator-activated receptor $\alpha$; $\mathrm{HBsAg}$, hepatitis $B$ virus surface antigen; AFP, $\alpha$-fetoprotein.

the study. In HCC patients with low PPAR $\alpha$ expression in the cytoplasm, the Kaplan-Meier analysis revealed that the patients had significantly worse outcomes in terms of overall survival $(P<0.001)$. Similar trends were observed for disease-free survival and the probability of recurrence, which showed that HCC patients with low PPAR $\alpha$ expression in the cytoplasm had significantly worse outcomes than those with high PPAR $\alpha$ expression in the cytoplasm, with worse disease-free survival $(P=0.024)$, and a higher probability of recurrence $(P=0.037)$, as shown in Figure 2 . 

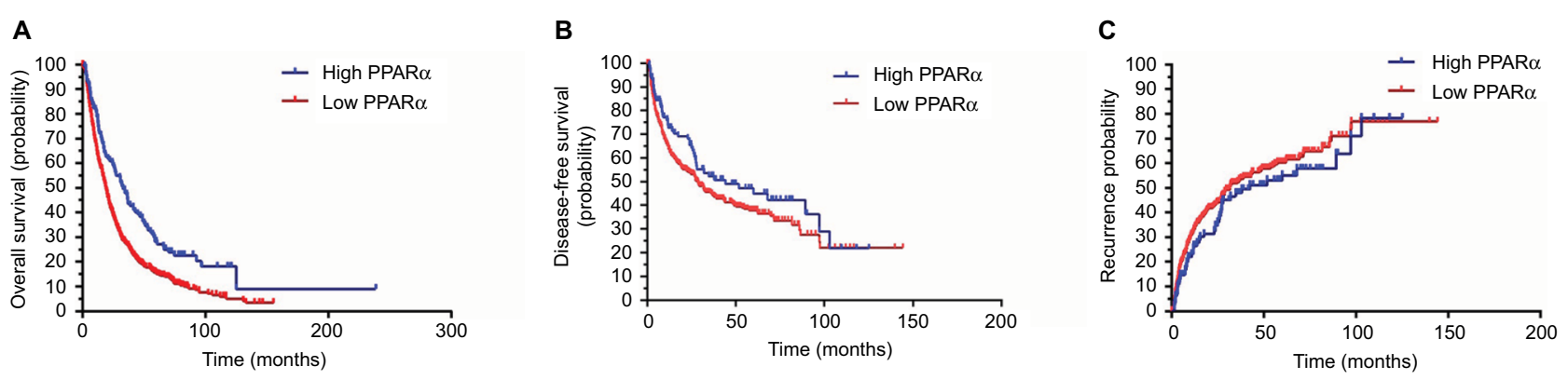

Figure 2 Low PPAR $\alpha$ (cytoplasm) expression is correlated with an unfavorable prognosis in 804 HCC patients.

Notes: Kaplan-Meier analysis shows significant differences in overall survival between postoperative HCC patients with high and low PPAR $\alpha$ (cytoplasm) expression (A). A similar trend was observed in HCC patients with high and low PPAR $\alpha$ (cytoplasm) expression comparing disease-free survival (B) and the probability of recurrence (C). Abbreviations: $\operatorname{PPAR} \alpha$, peroxisome proliferator-activated receptor $\alpha$; HCC, hepatocellular carcinoma.

We also conducted a Kaplan-Meier survival analysis to explore the differences in prognosis for HCC patients with both positive and negative PPAR $\alpha$ expression in the nucleus. The data indicated that HCC patients with negative PPAR $\alpha$ expression in the nucleus always had poorer outcomes, as shown in Figure 3. The overall survival was significantly shorter in HCC patients with negative PPAR $\alpha$ expression in the nucleus $(P=0.034)$. However, we did not find a prognostic impact of PPAR $\alpha$ expression in the nucleus in HCC patients with respect to disease-free survival and the probability of recurrence (data not shown).

\section{Univariate and multivariate analyses of prognostic variables in HCC}

To evaluate whether PPAR $\alpha$ expression was an independent risk factor for outcomes in HCC, both univariate and multivariate analyses were conducted. Age, serum $\alpha$-fetoprotein level, tumor size, tumor multiplicity, tumor differentiation, TNM stage, vascular invasion, involucrum, and PPAR $\alpha$ expression in the cytoplasm and nucleus were all shown to be prognostic variables for overall survival in HCC patients. In the multivariate analysis, only tumor size $(P=0.001)$, TNM stage $(P<0.001)$, vascular invasion $(P<0.001)$, and PPAR $\alpha$ expression in the cytoplasm $(P<0.001)$ were found to be independent prognostic variables for overall survival (Table 3 ).

\section{Subgroup analyses of prognostic value of PPAR $\alpha$ expression in the cytoplasm in HCC}

A stratified survival analysis was also conducted to further reveal the prognostic significance of PPAR $\alpha$ expression in the cytoplasm among HCC patients. The Kaplan-Meier survival analysis showed that PPAR $\alpha$ expression in the cytoplasm was associated with overall survival in both single and multiple HCCs (single HCCs: $P=0.001$, multiple HCCs: $P=0.003$ ),

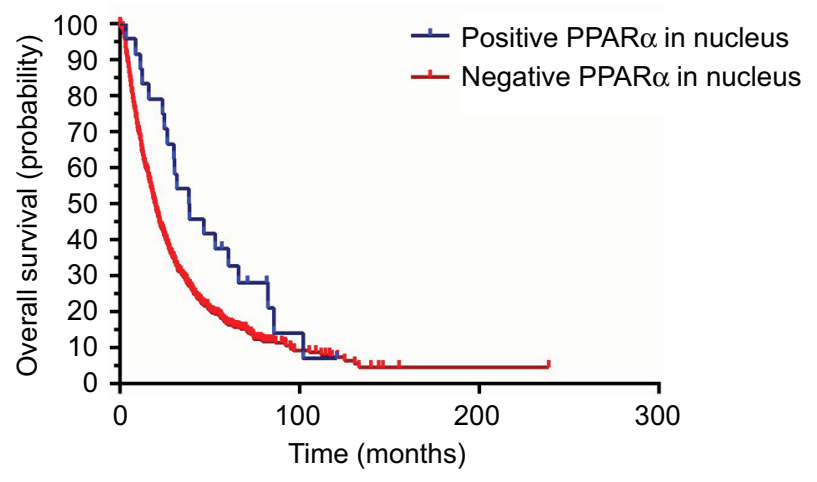

Figure 3 Positive PPAR $\alpha$ (nucleus) expression is correlated with favorable prognosis in HCC patients. Kaplan-Meier analysis shows significant differences in overall survival between HCC patients with positive and negative PPAR $\alpha$ (nucleus) expression. However, there was no significant difference observed with positive and negative PPAR $\alpha$ (nucleus) expression comparing disease-free survival and the probability of recurrence.

Abbreviations: PPAR $\alpha$, peroxisome proliferator-activated receptor $\alpha$; HCC, hepatocellular carcinoma.

in complete and incomplete involucrum HCCs (complete involucrum HCCs: $P=0.027$, incomplete involucrum HCCs: $P<0.001$ ), and in TNM stage I-II HCCs and III-IV HCCs (TNM stage I-II HCCs: $P=0.021$, TNM stage III-IV HCCs: $P<0.001)$, as shown in Figure 4.

\section{Discussion}

HCC is an end-stage liver disease with chronic viral infection accounting for most of the HCC etiology worldwide, especially in Asia. ${ }^{14-16}$ Recently, the rate of nutrient-associated HCC such as non-alcohol fatty liver disease-induced HCC has been found to be increasing. ${ }^{17,18}$ In addition, the reprogramming of energy metabolism is one of the hallmarks of cancer. ${ }^{19}$ Increasing evidence suggests that solid tumors might be also reliant on non-glucose carbon sources. ${ }^{19}$ Cancer cells show increased expression of enzymes involved in de novo fatty acid synthesis, which is very important for cellular biosynthesis such as in cell membranes. ${ }^{20}$ The more lipid 
Table 3 Univariate and multivariate analyses of prognostic variables for overall survival

\begin{tabular}{|c|c|c|c|c|c|c|}
\hline \multirow[t]{2}{*}{ Variables } & \multicolumn{3}{|c|}{ Univariate analysis } & \multicolumn{3}{|c|}{ Multivariate analysis } \\
\hline & HR & $95 \% \mathrm{Cl}$ & $P$ & HR & $95 \% \mathrm{Cl}$ & $P$ \\
\hline Age, years & 0.991 & $0.985-0.997$ & 0.004 & & & \\
\hline Gender & 0.872 & $0.684-1.112$ & 0.268 & & & \\
\hline $\mathrm{HBsAg}$ & 1.177 & $0.957-1.447$ & 0.123 & & & \\
\hline AFP & 1.252 & $1.046-1.499$ & 0.014 & & & \\
\hline Cirrhosis & 0.974 & $0.799-1.187$ & 0.794 & & & \\
\hline Tumor size, cm & 1.641 & $1.368-1.969$ & $<0.001$ & 1.382 & $1.146-1.666$ & 0.001 \\
\hline Tumor multiplicity & 1.634 & $1.395-1.915$ & $<0.001$ & & & \\
\hline Differentiation & 1.625 & $1.238-2.134$ & $<0.001$ & & & \\
\hline TNM & 2.074 & $1.77 \mid-2.429$ & $<0.001$ & 1.774 & $1.497-2.193$ & $<0.001$ \\
\hline Vascular invasion & 2.594 & $2.146-3.136$ & $<0.001$ & 1.785 & $1.453-2.193$ & $<0.001$ \\
\hline Involucrum & 1.373 & $1.176-1.603$ & $<0.001$ & 1.189 & $1.013-1.395$ & 0.034 \\
\hline PPAR $\alpha$ (cytoplasm) & 1.593 & $1.276-1.989$ & $<0.001$ & 1.595 & $1.274-1.997$ & $<0.001$ \\
\hline PPAR $\alpha$ (nucleus) & 1.612 & $1.033-2.517$ & 0.036 & & & \\
\hline
\end{tabular}

Abbreviations: HR, hazard ratio; PPAR $\alpha$, peroxisome proliferator-activated receptor $\alpha$; HBsAg, hepatitis $B$ virus surface antigen; AFP, $\alpha$-fetoprotein.
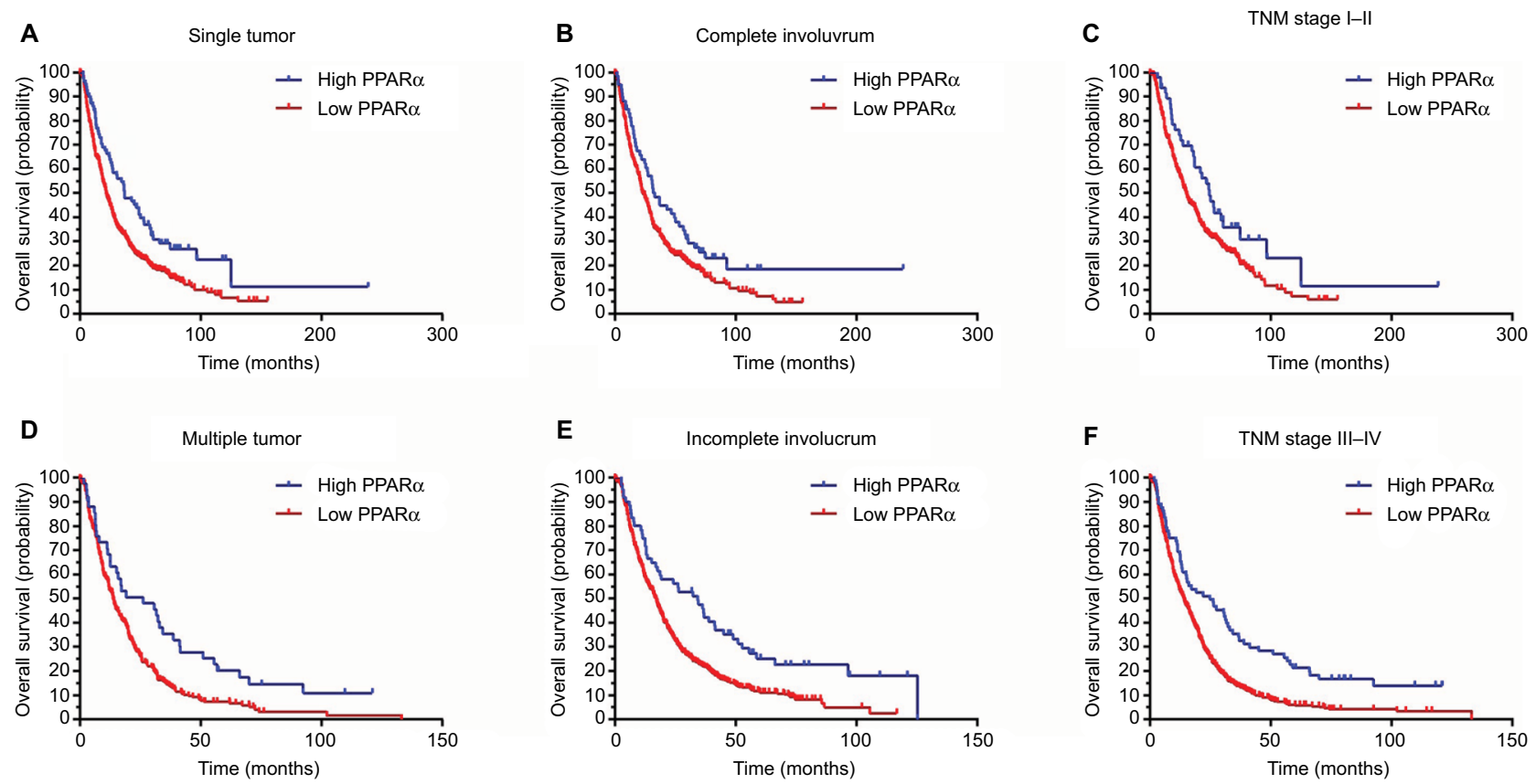

Figure 4 Low PPAR $\alpha$ (cytoplasm) expression is associated with unfavorable outcomes in subgroups of HCC patients.

Notes: A stratified survival analysis was conducted for PPAR $\alpha$ (cytoplasm) expression and unfavorable outcomes in single (A) and multinodular HCC (D), in HCCs with complete (B) and incomplete involucrum (E), in HCCs with TNM stage I-II (C) and stage III-IV (F).

Abbreviations: PPAR $\alpha$, peroxisome proliferator-activated receptor $\alpha$; HCC, hepatocellular carcinoma.

content in tumor cells, the higher the invasiveness. ${ }^{21}$ However, to increase lipid content for cellular biosynthesis, inhibition of lipid oxidation is a potential approach besides increasing de novo lipogenesis. PPAR $\alpha$ plays the central role in the lipid oxidation pathway in hepatocytes. Hence, we evaluated the expression of PPAR $\alpha$ in HCC and explored the relationship of PPAR $\alpha$ with HCC prognosis.

The PPAR family belongs to the nuclear hormone receptor superfamily. Like other nuclear hormone receptors, PPARs have four functional domains: amino-terminal domain, DNA binding domain, transcriptional activity regulation domains, and ligand binding domains. ${ }^{22,23}$ PPAR is located in the cytoplasm and when activated by ligands, it transforms into a heterodimer with retinoic X receptors (RXRs) or glucocorticoid receptor and then enters the nucleus and binds to the peroxisome proliferator response element to activate target gene transcription. ${ }^{22,24,25}$ Peroxisome proliferator response element is a specific DNA sequence located upstream of PPAR target genes. PPAR $\alpha$ is a member of the PPAR family, which contains three members: PPAR $\alpha, \operatorname{PPAR} \delta$, and PPAR $\gamma$. 
As the first protein identified in the PPAR family, PPAR $\alpha$ is mostly expressed in the liver and brown adipose tissue, followed by heart, kidney, and skeletal muscle, where it plays an important role in lipid metabolism. Previous reports have shown that PPAR $\alpha$ plays an important role in regulating cell proliferation and maintaining the metabolic balance in cells, regulating tumorigenesis, as well as other cell biology processes. ${ }^{23}$ However, there are controversial data surrounding the role of PPAR $\alpha$ in tumorigenesis.

In colon cancer, it is well-established that sustained chronic colon inflammation can promote the occurrence of colon cancer. One study reported that increased PPAR $\alpha$ expression could inhibit the expression of pro-inflammatory cytokines such as interleukin-17 and interferons $\gamma$, which implies an anti-tumorigenic effect of PPAR $\alpha$ in colon cancer. ${ }^{26}$ In breast cancer, one study found lack of PPAR $\alpha$ expression in patients with basal-like breast cancer. ${ }^{27}$ In human breast cancer (MCF-7) and human cervical cancer (A2780) cell lines, PPAR $\alpha$ reduces the expression of VEGF by promoting the ubiquitination of hypoxia inducible factor alpha. ${ }^{28}$ On the other hand, studies have also revealed the tumorigenic impact of PPAR $\alpha$ in breast cancer. PPAR $\alpha$ can be activated by leukotrienes produced by regulatory $\mathrm{B}$ cells and in this way promote cancer metastasis. ${ }^{29}$ Activating PPAR $\alpha$ can also lead to the upregulation of the expression of cyclin $\mathrm{E}$ and the promotion of breast cancer proliferation. ${ }^{30}$ The role of PPAR $\alpha$ in cancer is still unknown and requires further exploration. It is possible that $\operatorname{PPAR} \alpha$ activation could reduce or promote tumorigenesis, depending on the type of tissue and different PPAR $\alpha$ ligands. Especially in HCC, since PPAR $\alpha$ is primarily expressed in liver tissue, the role of PPAR $\alpha$ in HCC tumorigenesis is still unknown. Activation of PPAR $\alpha$ has effects on fatty acid catabolism, hepatocyte proliferation, hepatomegaly, and is closely related to the occurrence of HCC. ${ }^{31}$ However, fenofibrate, an oral agonist of PPAR $\alpha$, can inhibit the proliferation of Huh7 cells, an HCC cell line, by inhibiting the Akt pathway. ${ }^{32}$ It is also well-known that sustained activation of PPAR $\alpha$ induces $\mathrm{HCC}$ in rodents. ${ }^{33}$

In this study, we found that the expression of PPAR $\alpha$ in HCC tissue was significantly lower than in normal liver tissue. Interestingly, we found that PPAR $\alpha$ is mainly expressed in the cytoplasm of liver cancer cells, with only a small fraction of cancer cells expressing PPAR $\alpha$ in the nucleus. In the cytoplasm, following activation by ligands such as fatty acids, PPAR $\alpha$ forms a heterodimer after which it translocates from the cytoplasm to the nucleus, ${ }^{34}$ where the heterodimer acts as a transcription factor by binding to peroxisome proliferator response elements located upstream of target genes, thus activating target gene transcription. In this way, PPAR $\alpha$ regulates lipid oxidation, inflammation, and immune-related gene expression. ${ }^{34}$ Based on the results of our study, we believe that PPAR $\alpha$ activation is inhibited in HCC cells. The mechanism underlying this may be that inhibition of PPAR $\alpha$ activation will inhibit fatty acid oxidation, thereby increasing the intracellular lipid content, which can then be used to synthesize important cellular constituents such as cell membranes, or for use as an energy store to deal with metabolic stress, as has previously been reported. ${ }^{7}$ However, this hypothesis needs to be explored further.

Based on the results of our study, we found that a high level of PPAR $\alpha$ expression in the cytoplasm was associated with smaller tumor sizes, less vascular invasion, and a higher proportion of complete involucrum. Similarly, positive PPAR $\alpha$ expression in the nucleus was often accompanied with a smaller tumor size and a significantly lower proportion of poor, undifferentiated tumors, tumors at TNM stage III-IV, and an incomplete involucrum. Previous studies have reported that activating PPAR $\alpha$ can inhibit cancer cell growth and reduce vessel formation. ${ }^{28,35}$ In HCC, PPAR $\alpha$ may play a similar role in reducing $\mathrm{HCC}$ cell proliferation and vessel formation, since our data indicated that high PPAR $\alpha$ expression in the cytoplasm and positive PPAR $\alpha$ expression in the nucleus are accompanied by smaller tumor sizes and less vascular invasion. The specific role of PPAR $\alpha$ in the development of HCC needs to be studied further to confirm this hypothesis.

The prognostic implications of PPAR $\alpha$ expression in $\mathrm{HCC}$ have not been previously reported. In our study, PPAR $\alpha$ was identified as an independent factor for overall survival in a large cohort of 804 patients with HCC. Patients with high levels of PPAR $\alpha$ expression usually survived for a longer period. These data suggest that PPAR $\alpha$ expression has clinical implications in predicting outcomes in HCC patients. PPAR $\alpha$ is a major regulator of lipid metabolism in the liver; the relationship between liver fat content and PPAR $\alpha$ expression needs to be further explored. In addition, in our study, only PPAR $\alpha$ expression in HCC cell cytoplasm was prognostic for disease-free survival and the probability of recurrence. To further confirm the prognostic effect of PPAR $\alpha$ expression in the nucleus for disease-free survival and the probability of recurrence among HCC patients, further study will be required involving more patients positive for PPAR $\alpha$ expression in the HCC cell nucleus.

Retinoids and their receptors have a close relationship with PPAR. ${ }^{36,37}$ RXRs and retinoic acid receptors (RAR) are two main nuclear receptors binding with retinoids. Retinoids 
are a group of structural and functional analogs of vitamin A and play an important role in the regulation of cell proliferation and differentiation. ${ }^{38,39}$ Both RXR and RAR are composed of three subtypes, $\alpha, \beta$, and $\gamma$. RAR binds with 9-cis retinoic acid and all-trans-retinoic acid while RXR only binds with 9-cis retinoic acid. A study reported that $\mathrm{RXR} \alpha$ was decreased not only in HCC, but also in the early stage of liver carcinogenesis. ${ }^{40,41}$ In addition, studies have also revealed that hepatocarcinogenesis is accompanied by the accumulation of a phosphorylated form of $\operatorname{RXR} \alpha$, which is an inactive form of $\operatorname{RXR} \alpha$ and abolishes its ability to form heterodimers with other nuclear receptors. ${ }^{42}$ Evidence focusing on the relationship between RAR and HCC is still limited. Studies show that $R A R \beta$ is a tumor suppressor gene. ${ }^{43}$ Enhanced RAR $\beta$ expression correlates with the growth inhibitory effect of cancer cells and the absence of RAR $\beta$ expression is accompanied with tumor progression. ${ }^{44}$ In addition, overexpression RAR $\beta$ by vector induce drug sensitivity of tumor cells and suppresses proliferation. ${ }^{45}$ However, the specific role of RXR subtypes and RAR subtypes in HCC still needs further exploration.

In summary, our data demonstrate a role for PPAR $\alpha$ in the development of HCC. Data reveal that PPAR $\alpha$ expression is decreased in HCC samples and, unlike PPAR $\alpha$ in rodent liver, PPAR $\alpha$ in human HCC may have an antitumor effect. Increases in PPAR $\alpha$ expression were significantly correlated with improved tumor differentiation and less vascular invasion. High PPAR $\alpha$ expression was correlated with longer survival times in HCC patients and served as an independent factor for better outcomes. Collectively, our data suggest that PPAR $\alpha$ is a promising biomarker for the prognosis of patients with HCC.

\section{Acknowledgments}

This study was supported by grants from the National Key R\&D Program of China (2017YFC1309000), National Natural Science Foundation of China (nos 81572405, 81572406, $81502079,81602135)$, and Science and Technology Program of Guangzhou (201707020038).

\section{Disclosure}

The authors report no conflicts of interest in this work.

\section{References}

1. Forner A, Reig M, Bruix J. Hepatocellular carcinoma. Lancet. 2018;391:1301-1314.

2. Cai SH, Lu SX, Liu LL, Zhang CZ, Yun JP. Increased expression of hepatocyte nuclear factor 4 alpha transcribed by promoter 2 indicates a poor prognosis in hepatocellular carcinoma. Therap Adv Gastroenterol. 2017;10:761-771.
3. Chen SL, Liu LL, Lu SX, et al. HBX-mediated decrease of AIM2 contributes to hepatocellular carcinoma metastasis. Mol Oncol. 2017;11: 1225-1240.

4. Vander HM, Cantley LC, Thompson CB. Understanding the Warburg effect: the metabolic requirements of cell proliferation. Science. 2009;324:1029-1033.

5. Nieman KM, Kenny HA, Penicka CV, et al. Adipocytes promote ovarian cancer metastasis and provide energy for rapid tumor growth. Nat Med. 2011;17:1498-1503.

6. Hirayama A, Kami K, Sugimoto M, et al. Quantitative metabolome profiling of colon and stomach cancer microenvironment by capillary electrophoresis time-of-flight mass spectrometry. Cancer Res. 2009;69:4918-4925.

7. Wang MD, Wu H, Fu GB, et al. Acetyl-coenzyme A carboxylase alpha promotion of glucose-mediated fatty acid synthesis enhances survival of hepatocellular carcinoma in mice and patients. Hepatology. 2016;63:1272-1286.

8. Chung S, Kim YJ, Yang SJ, Lee Y, Lee M. Nutrigenomic functions of PPARs in obesogenic environments. PPAR Res. 2016;2016:4794576.

9. Mello T, Materozzi M, Galli A. PPARs and mitochondrial metabolism: from NAFLD to HCC. PPAR Res. 2016;2016:7403230.

10. Youssef J, Badr M. Peroxisome proliferator-activated receptors and cancer: challenges and opportunities. Br J Pharmacol. 2011;164:68-82.

11. Suchanek KM, May FJ, Robinson JA, et al. Peroxisome proliferatoractivated receptor alpha in the human breast cancer cell lines MCF-7 and MDA-MB-231. Mol Carcinog. 2002;34:165-171.

12. Abu AO, Wettersten HI, Weiss RH. Inhibition of PPAR $\alpha$ induces cell cycle arrest and apoptosis, and synergizes with glycolysis inhibition in kidney cancer cells. PLoS One. 2013;8:e71115.

13. Peters JM, Cattley RC, Gonzalez FJ. Role of PPAR alpha in the mechanism of action of the nongenotoxic carcinogen and peroxisome proliferator Wy-14,643. Carcinogenesis. 1997;18:2029-2033.

14. Cai S, Cao J, Yu T, Xia M, Peng J. Effectiveness of entecavir or telbivudine therapy in patients with chronic hepatitis B virus infection pretreated with interferon compared with de novo therapy with entecavir and telbivudine. Medicine (Baltimore). 2017;96:e7021.

15. Cai S, Yu T, Jiang Y, Zhang Y, Lv F, Peng J. Comparison of entecavir monotherapy and de novo lamivudine and adefovir combination therapy in $\mathrm{HBeAg}$-positive chronic hepatitis B with high viral load: 48-week result. Clin Exp Med. 2016;16:429-436.

16. Cai SH, Lv FF, Zhang YH, Jiang YG, Peng J. Dynamic comparison between Daan real-time PCR and Cobas TaqMan for quantification of HBV DNA levels in patients with CHB. BMC Infect Dis. 2014;14:85.

17. Ou H, Cai S, Liu Y, Xia M, Peng J. A noninvasive diagnostic model to assess nonalcoholic hepatic steatosis in patients with chronic hepatitis B. Therap Adv Gastroenterol. 2017;10:207-217.

18. Shaohang C, Zejin O, Duan L, et al. Risk factors associated with liver steatosis and fibrosis in chronic hepatitis B patient with component of metabolic syndrome. United Eur Gastroenterol J. 2018;6:558-566.

19. Pavlova NN, Thompson CB. The emerging hallmarks of cancer metabolism. Cell Metab. 2016;23:27-47.

20. Sunami Y, Rebelo A, Kleeff J. Lipid metabolism and lipid droplets in pancreatic cancer and stellate cells. Cancers (Basel). 2017;10:E3.

21. Li Z, Kang Y. Lipid metabolism fuels cancer's spread. Cell Metab. 2017;25:228-230.

22. Han L, Shen WJ, Bittner S, Kraemer FB, Azhar S. PPARs: regulators of metabolism and as therapeutic targets in cardiovascular disease. Part I: PPAR-alpha. Future Cardiol. 2017;13:259-278.

23. Gao J, Yuan S, Jin J, Shi J, Hou Y. PPAR $\alpha$ regulates tumor progression, foe or friend? Eur J Pharmacol. 2015;765:560-564.

24. Huang JY, Bi Y, Zuo GW, Feng T. Effects of HBx on localization of PPAR $\gamma$ in HepG2 cell line. Acta Academiae Medicinae Militaris Tertiae. 2008;18:1693-1696.

25. Moran EP, Ma JX. Therapeutic effects of PPAR alpha on neuronal death and microvascular impairment. PPAR Res. 2015;2015:595426.

26. Lee JW, Bajwa PJ, Carson MJ, et al. Fenofibrate represses interleukin-17 and interferon-gamma expression and improves colitis in interleukin10-deficient mice. Gastroenterology. 2007;133:108-123. 
27. Baker BG, Ball GR, Rakha EA, et al. Lack of expression of the proteins GMPR2 and PPAR $\alpha$ are associated with the basal phenotype and patient outcome in breast cancer. Breast Cancer Res Treat. 2013;137:127-137.

28. Zhou J, Zhang S, Xue J, et al. Activation of peroxisome proliferatoractivated receptor $\alpha$ (PPAR $\alpha)$ suppresses hypoxia-inducible factor- $1 \alpha$ (HIF-1 $\alpha$ ) signaling in cancer cells. J Biol Chem. 2012;287:35161-35169.

29. Wejksza K, Lee-Chang C, Bodogai M, et al. Cancer-produced metabolites of 5-lipoxygenase induce tumor-evoked regulatory $\mathrm{B}$ cells via peroxisome proliferator-activated receptor alpha. J Immunol. 2013;190:2575-2584.

30. Chang NW, Wu CT, Chen DR, Yeh CY, Lin C. High levels of arachidonic acid and peroxisome proliferator-activated receptor-alpha in breast cancer tissues are associated with promoting cancer cell proliferation. J Nutr Biochem. 2013;24:274-281.

31. Scalera A, Tarantino G. Could metabolic syndrome lead to hepatocarcinoma via non-alcoholic fatty liver disease? World J Gastroenterol. 2014;20:9217-9228.

32. Yamasaki D, Kawabe N, Nakamura H, et al. Fenofibrate suppresses growth of the human hepatocellular carcinoma cell via PPAR $\alpha$ independent mechanisms. Eur J Cell Biol. 2011;90:657-664.

33. Tanaka N, Moriya K, Kiyosawa K, Koike K, Gonzalez FJ, Aoyama T. PPAR $\alpha$ activation is essential for HCV core protein-induced hepatic steatosis and hepatocellular carcinoma in mice. J Clin Invest. 2008;118:683-694.

34. Adeghate E, Adem A, Hasan MY, Tekes K, Kalasz H. Medicinal chemistry and actions of dual and pan PPAR modulators. Open Med Chem J. 2011;5:93-98.

35. Martinasso G, Oraldi M, Trombetta A, et al. Involvement of PPARs in cell proliferation and apoptosis in human colon cancer specimens and in normal and cancer cell lines. PPAR Res. 2007;2007:93416.
36. Wagner CE, Jurutka PW, Marshall PA, Heck MC. Retinoid X receptor selective agonists and their synthetic methods. Curr Top Med Chem. 2017; 17:742-767.

37. Tripathy S, Chapman JD, Han CY, et al. All-trans-retinoic acid enhances mitochondrial function in models of human liver. Mol Pharmacol. 2016;89:560-574.

38. Mark M, Ghyselinck NB, Chambon P. Function of retinoid nuclear receptors: lessons from genetic and pharmacological dissections of the retinoic acid signaling pathway during mouse embryogenesis. Annu Rev Pharmacol Toxicol. 2006;46:451-480.

39. Chambon P. A decade of molecular biology of retinoic acid receptors. FASEB J. 1996;10:940-954.

40. Hoshikawa Y, Kanki K, Ashla AA, et al. c-Jun N-terminal kinase activation by oxidative stress suppresses retinoid signaling through proteasomal degradation of retinoic acid receptor $\alpha$ protein in hepatic cells. Cancer Sci. 2011;102:934-941.

41. Matsushima-Nishiwaki R, Shidoji Y, Nishiwaki S, Yamada T, Moriwaki H, Muto Y. Aberrant metabolism of retinoid X receptor proteins in human hepatocellular carcinoma. Mol Cell Endocrinol. 1996;121:179-190.

42. Yoshimura K, Muto Y, Shimizu M, et al. Phosphorylated retinoid X receptor alpha loses its heterodimeric activity with retinoic acid receptor beta. Cancer Sci. 2007;98:1868-1874.

43. Moore DM, Kalvakolanu DV, Lippman SM, et al. Retinoic acid and interferon in human cancer: mechanistic and clinical studies. Semin Hematol. 1994;31:31-37.

44. Lippman SM, Lotan R. Advances in the development of retinoids as chemopreventive agents. J Nutr. 2000;130:479S-482S.

45. Sun SY, Lotan R. Retinoids and their receptors in cancer development and chemoprevention. Crit Rev Oncol Hematol. 2002;41:41-55.
Cancer Management and Research

\section{Publish your work in this journal}

Cancer Management and Research is an international, peer-reviewed open access journal focusing on cancer research and the optimal use of preventative and integrated treatment interventions to achieve improved outcomes, enhanced survival and quality of life for the cancer patient. The manuscript management system is completely online and includes

\section{Dovepress}

a very quick and fair peer-review system, which is all easy to use. Visit http://www.dovepress.com/testimonials.php to read real quotes from published authors. 